\title{
Risks of Propofol-based Total Intravenous Anesthesia Compared with Local Anesthesia in Patients Undergoing Percutaneous Transluminal Angioplasty in The Lower Extremity
}

Wejpisit Wongwiwattananon, M.D., Jatuporn Pakpirom, M.D., Raviwan Akarapatima, M.D.

Department of Anesthesiology, Faculty of Medicine, Prince of Songkla University, Hat Yai, Songkhla 90110, Thailand.

Received 17 February 2020 • Revised 23 April 2020 • Accepted 24 April 2020 • Published online 15 June 2020

\begin{abstract}
:
Objective: This study aimed to determine the risks of propofol-based total intravenous anesthesia (TIVA) compared to local anesthesia (LA) in patients undergoing percutaneous transluminal angioplasty (PTA) in a lower extremity.
\end{abstract}

Material and Methods: A retrospective cohort study was conducted in 231 patients who underwent PTA in the lower extremity using either propofol-based TIVA or LA between January 2016 and September 2018. The outcomes of interest included perioperative major adverse cardiac events (MACE) and minor perioperative complications. Risk factors analysis was performed using a univariate logistic regression and backward stepwise multivariate logistic regression.

Results: Although the rate of perioperative MACE was two times higher in the propofol-based TIVA group (7.8\%) than the LA group (3.9\%), no significant difference was found ( $p$-value=0.221). The propofol-based TIVA group had a significantly higher incidence of all minor perioperative complications than the LA group (77.6\% vs $13.6 \%, p-v a l u e<0.001)$. Multivariate analysis found that low body mass index (BMI) and American Society of Anesthesiologists classification III were independent factors associated with perioperative MACE, while propofol-based TIVA, body weight (or BMI), hypertension, diabetes mellitus, previous coronary artery disease, and previous congestive hear failure were associated with perioperative minor complications.

Conclusion: Based on this study, no significant differences in perioperative MACE were found using either TIVA or LA. However, TIVA produced a significantly higher incidence of perioperative minor complication than LA. Close intraoperative monitoring should be implemented when using propofol-based TIVA in patients undergoing PTA in the lower extremity.

Keywords: critical limb ischemia, local anesthesia, percutaneous transluminal angioplasty, peripheral artery disease, propofol-based total intravenous anesthesia

Contact: Wejpisit Wongwiwattananon, M.D.

Department of Anesthesiology, Faculty of Medicine, Prince of Songkla University, Hat Yai, Songkhla 90110, Thailand.

E-mail: wejpisit@gmail.com

Hosting by Prince of Songkla University. All rights reserved.

This is an open access article under the CC BY-NC-ND license

(http://www.jhsmr.org/index.php/jhsmr/about/editorialPolicies\#openAccessPolicy).

J Health Sci Med Res 2020;38(4):275-284 doi: 10.31584 /jhsmr.2020747 www.jhsmr.org 


\section{Introduction}

Approximately 202 million people had peripheral artery disease in 2010 and more than half of them were in either low-income or middle-income countries. ${ }^{1}$ Due to aging populations, a growing number of vascular patients have multiple medical conditions that can cause an increase in the risks of doing conventional surgical revascularization procedures in the lower extremity. Hence, there has been a shift toward less invasive procedures using percutaneous transluminal angioplasty (PTA) to revascularize peripheral arterial disease in the lower extremities. $^{2}$

The advantages of PTA over surgical revascularization at the lower extremities include lower morbidities, less cardiovascular stress, and the ability to perform the procedure under local anesthesia $(\mathrm{LA}) .^{3-6}$ In particular regions, such as the United States of America, PTA is performed under local anesthesia and sedation in an interventional radiology suite rather than under general anesthesia. However, European countries prefer performing the procedure under general anesthesia in an operating theater. This might be because of higher patient expectations and patient anxiety under local anesthesia., ${ }^{7,8}$ Therefore, propofol-based total intravenous anesthesia (TIVA) is the preferable choice to overcome patient anxiety during the procedure. At our institute, PTA in a lower extremity had been performed with only local anesthesia by interventional radiologist in the past 10 years because of unavailable personnel from the anesthesiology department. Recently, anesthesiologist had provided service for interventional radiologist, which then almost all cases routinely underwent PTA with propofol-based TIVA because of the mutual preference of the interventional radiologists and the anesthesiologists.

It was reported that the choice of anesthetic technique could impact the perioperative outcomes in certain operations. ${ }^{9-11}$ Nevertheless, the choice of the anesthetic technique in other procedures may favor locoregional anesthesia, but the current evidence remains controversial. ${ }^{12-19}$ Several studies of PTA in the lower extremity focused mostly on long-term surgical outcomes. ${ }^{20-24}$ However, the number of studies which considered perioperative major adverse cardiac events (MACE) along with other minor perioperative complications is limited. ${ }^{25,26}$ In addition, the effect on cardiovascular and respiratory depression of propofol-based TIVA in patients undergoing PTA in the lower extremity can be unpredictable because of advanced age and multiple medical comorbidities. The aim of this study was to determine the risks of propofolbased TIVA in patients undergoing PTA in the lower extremity.

\section{Material and Methods}

A retrospective cohort study was conducted in a university-based tertiary care hospital and is the referral center for vascular intervention in southern Thailand. Approval for the study was received from the Ethics Committee of the Faculty of Medicine, Prince of Songkla University. Eligible patients were identified from the hospital information system database from January 2016 to September 2018 using search terms with specific International Classification of Diseases, Tenth Revision (ICD-10) codes that included (1) peripheral artery disease, unspecified (1739) and (2) performing PTA under ICD-9AM with the codes 3950 and 8848 . The patients included in the study were over 18 years old who underwent PTA in their lower extremity and underwent the procedure under either propofol-based TIVA or LA. Those who had continuous infusion of vasopressor before the operation were excluded from the study. All of the procedures in our hospital were performed in the interventional radiology suite. All patients in the LA group received local infiltration by an interventional radiologist at the femoral puncture site without an attending anesthesiologist, whereas propofol-based TIVA was provided by the anesthesia team. 
Both groups received the same standard American Society of Anesthesiologists (ASA) monitoring, which included pulse oximetry, blood pressure, and electrocardiogram. In addition, the end-tidal capnography was monitored in the propofol-based TIVA group. The interval of blood pressure recording time was every 15 minutes in the LA group, and every 5 minutes in the propofol-based TIVA group. Every patient in both groups received supplemental oxygen before the procedure.

The primary outcomes were perioperative MACE and minor perioperative complications. Perioperative MACE was defined and recorded if patients developed the following perioperative events: (1) fatal arrhythmia (ventricular tachycardia, ventricular fibrillation, and complete heart block); (2) congestive heart failure (CHF); (3) myocardial infarction; (4) stroke; (5) cardiac arrest; and (6) death. Minor perioperative complications were defined as: (1) hypotension; (2) arrhythmia; (3) airway intervention; (4) vasopressor requirement during operation; and (5) continuous vasopressor infusion during and within 24 hours of the operation. Hypotension was defined as mean arterial pressure $<65$ millimetre of mercury $(\mathrm{mmHg})$ or $20.0 \%$ of baseline in hypertensive patients. Any airway interventions needed during the operation or within 24 hours after the operation that included positive pressure ventilation with a facemask, laryngeal mask airway insertion, or endotracheal intubation were defined as airway intervention. Operation time was the duration the patient remained in the operation room.

Baseline patient characteristics, underlying diseases, and surgical factors were reviewed and recorded from the anesthetic and medical records in the hospital information system as independent variables. Patient characteristic information included age, sex, body weight, height, body mass index (BMI), and ASA classification. Other collected data included underlying diseases including diabetes, hypertension, previous CHF, previous coronary artery disease $(C A D)$, previous stroke, and creatinine $>2$ milligram per deciliter $(\mathrm{mg} / \mathrm{dL})$. Also recorded were the clinical presentations that were either intermittent claudication or critical limb ischemia and the site of arterial occlusion.

The sample size was calculated based on the formula of the two-proportion difference of prevalence of perioperative MACE between $1.0 \%$ of $\mathrm{LA}^{26}$ and $12.0 \%$ of propofol-based TIVA. A total of 231 patients were required of which 154 patients were in the LA group and 77 patients were in the propofol-based TIVA group to provide $80.0 \%$ power. The level of significance was set at 0.05 and the ratio between the LA group and propofol-based TIVA group was equal to $2: 1$. For the statistical analysis, we used R software v.3.4.5 (R Foundation for Statistical Computing, Vienna, Austria). Continuous variables, such as age, height, body weight, and operative time are reported as mean \pm standard deviation (S.D.) or median (interquartile range; IQR) depending on which one was appropriate for distribution of the data. Discrete variables are reported as frequency and percentage. The chi-square test or Fisher's exact test was used as appropriate to compare the difference of categorical variables between the two groups. Unpaired student $t$-test or Mann-Whitney $U$ test was used to test the difference of continuous variables between the two groups. Univariate analysis and backward stepwise multivariate logistic regression were used to find the associated factors of perioperative MACE and minor complications.

\section{Results}

The baseline patient characteristics of 231 patients that included underlying diseases, surgical factors, and clinical presentation are presented in Table 1. The mean \pm S.D. age of the patients was $69.9 \pm 13.0$ years (range $30-97$ years) and $64.1 \%$ were male. The proportion of ASA classification III is higher in the propofol-based TIVA group. More than half of the patients had hypertension and diabetes mellitus while almost one quarter of the 
Table 1 Baseline patient characteristic, underlying diseases, and clinical presentations

\begin{tabular}{ll}
\hline Patient characteristics & $\mathbf{n = 2 3 1}$ \\
\hline Age, years, mean \pm S.D. & $69.9 \pm 13.0$ \\
Sex & \\
Male & $148(64.1)$ \\
Female & $83(35.9)$ \\
Body weight, kg, mean \pm S.D. & $56.8 \pm 10.8$ \\
Height, cm, mean \pm S.D. & $160.8 \pm 8.2$ \\
Body mass index, kg/m², mean \pm S.D. & $21.9 \pm 3.6$ \\
ASA classification & \\
ASA class I & $3(1.3)$ \\
ASA class II & $115(49.8)$ \\
ASA class III & $113(48.9)$ \\
Underlying disease & \\
Hypertension & $177(76.6)$ \\
Diabetes mellitus & $120(51.9)$ \\
Previous CAD & $45(19.5)$ \\
Previous CHF & $15(6.5)$ \\
Previous stroke & $20(8.7)$ \\
Creatinine $>2$ mg/dL & $56(24.2)$ \\
Clinical presentation & \\
Claudication & $54(23.4)$ \\
Critical limb ischemia & $177(76.6)$ \\
\hline
\end{tabular}

Data are presented as $\mathrm{n}(\%)$ unless indicated otherwise.

S.D.=standard deviation, $\mathrm{kg}=\mathrm{kilogram}, \mathrm{cm}=$ centimeter, $\mathrm{m}^{2}=$ square meter, $\mathrm{ASA}=\mathrm{American}$ Society of Anesthesiologists, $\mathrm{CAD}=$ coronary artery disease, $\mathrm{CHF}=$ congestive heart failure, $\mathrm{mg} / \mathrm{dL}=$ milligram per deciliter, $\mathrm{n}=$ number patients had impaired renal function (creatinine $>2 \mathrm{mg} / \mathrm{dL}$ ). The majority of cases presented with critical limb ischemia (76.6\%) which was more than claudication (23.4\%). The median IQR operation time in the propofol-based TIVA group was higher than the LA group $[135(105,165)$ vs $125(105,150)]$ without significant difference ( $p-$ value= 0.293). There was no statistically significant difference in the baseline characteristics between the LA group and the propofol-based TIVA group, except the LA group had a significantly higher number of patients with diabetes mellitus than the propofol-based TIVA group $(58.4 \%$ vs $39.0 \%, p$-value=0.008) (Table 2).

Perioperative complications, including MACE and minor perioperative complications in both the LA group and propofol-based TIVA group are presented in Table 3. Although the rate of perioperative MACE in the propofolbased TIVA group (7.8\%) was two times higher than the LA group (3.9\%), no significant difference was found ( $p$-value=0.221). However, a statistically significantly higher proportion of patients were found to have minor complications (hypotension, arrhythmia, airway intervention, vasopressor needed, and continuous vasopressor infusion) in the propofol-based TIVA group than in the LA group.

Table 2 Patient characteristics and underlying diseases for both the local anesthesia group and propofol-based total intravenous anesthesia group

\begin{tabular}{|c|c|c|c|}
\hline Patient characteristics & $\begin{array}{l}\text { Local anesthesia } \\
(n=154)\end{array}$ & $\begin{array}{l}\text { Propofol-based TIVA } \\
(n=77)\end{array}$ & $p$-value \\
\hline Age, years, median (IQR) & $71(61.0,79.0)$ & $74(64.0,80.0)$ & 0.243 \\
\hline Sex & & & 0.734 \\
\hline Male & $97(63.0)$ & $51(66.2)$ & \\
\hline Female & $57(37.0)$ & $26(33.8)$ & \\
\hline Body weight, kg, median (IQR) & $58(50.0,65.0)$ & $54(47.0,63.0)$ & 0.123 \\
\hline Height, cm, mean \pm S.D. & $160.6 \pm 7.7$ & $161 \pm 9.2$ & 0.722 \\
\hline Body mass index, mean \pm S.D. & $22.2 \pm 3.5$ & $21.3 \pm 3.8$ & 0.068 \\
\hline ASA classification & & & 0.019 \\
\hline ASA classification I-II & $87(56.4)$ & $31(40.3)$ & \\
\hline ASA classification III & $67(43.5)$ & $46(59.7)$ & \\
\hline
\end{tabular}


Table 2 (continued)

\begin{tabular}{llll}
\hline Patient characteristics & $\begin{array}{l}\text { Local anesthesia } \\
(\mathbf{n = 1 5 4 )}\end{array}$ & $\begin{array}{l}\text { Propofol-based TIVA } \\
(\mathbf{n = 7 7})\end{array}$ & p-value \\
\hline Hypertension & $116(75.3)$ & $61(79.2)$ & 0.621 \\
Diabetes mellitus & $90(58.4)$ & $30(39.0)$ & 0.008 \\
Previous CAD & $28(18.2)$ & $17(22.1)$ & 0.597 \\
Previous CHF & $11(7.1)$ & $4(5.2)$ & 0.777 \\
Previous stroke & $12(7.8)$ & $8(10.4)$ & 0.679 \\
Creatinine $>$ 2 mg/dL & $42(27.3)$ & $14(18.2)$ & 0.175 \\
Received fentanyl & $43(27.9)$ & $77(100.0)$ & $<0.001$ \\
Fentanyl dosage, mcg, median (IQR) & $0(0.0,30.0)$ & $100(75.0,125.0)$ & $<0.001$ \\
Received midazolam & $11(7.1)$ & $33(42.9)$ & $<0.001$ \\
Midazolam dosage, mg, median (IQR) & $0(0.0,0.0)$ & $0(0.0,1.0)$ & $<0.001$ \\
Propofol dosage, mg, median (IQR) & $0(0.0,0.0)$ & $454(298.0,724.0)$ & \\
\hline
\end{tabular}

Data are presented as $\mathrm{n}(\%)$ unless indicated otherwise.

TIVA=total intravenous anesthesia, IQR, interquartile range, $\mathrm{kg}=\mathrm{kilogram}, \mathrm{S} . \mathrm{D} .=$ standard deviation, $\mathrm{ASA}=\mathrm{American}$ Society of Anesthesiologists, $\mathrm{CAD}=$ coronary artery disease, $\mathrm{CHF}=$ congestive heart failure, $\mathrm{mg} / \mathrm{dL}=$ milligram per deciliter, $\mathrm{n}=$ number; $\mathrm{mcg}=$ microgram; $\mathrm{mg}=$ milligram

Table 3 Perioperative complications in the local anesthesia group and propofol-based total intravenous anesthesia group

\begin{tabular}{llll}
\hline Perioperative complications & $\begin{array}{l}\text { Local anesthesia } \\
(\mathbf{n = 1 5 4 )}\end{array}$ & $\begin{array}{l}\text { Propofol-based TIVA } \\
(\mathbf{n = 7 7 )}\end{array}$ & $\mathbf{p}$-value \\
\hline Perioperative MACE & $6(3.9)$ & $6(7.8)$ & 0.221 \\
Fatal arrhythmia & $1(0.6)$ & $2(2.6)$ & 0.258 \\
Myocardial infarction & $3(1.9)$ & $1(1.3)$ & 1.000 \\
Congestive heart failure & $2(1.3)$ & $2(2.6)$ & 0.602 \\
Stroke & $0(0.0)$ & $1(1.3)$ & 0.333 \\
Cardiac arrest & $3(1.9)$ & $0(0.0)$ & 0.553 \\
Death & $2(1.3)$ & $2(2.6)$ & 0.602 \\
Minor complications & $21(13.6)$ & $59(77.6)$ & $<0.001$ \\
Hypotension & $18(11.7)$ & $58(75.3)$ & $<0.001$ \\
Arrhythmia & $5(3.2)$ & $10(13.0)$ & 0.011 \\
Airway intervention & $2(1.3)$ & $11(14.3)$ & $<0.001$ \\
Vasopressor needed & $3(1.9)$ & $38(49.4)$ & $<0.001$ \\
Continuous vasopressor & $3(1.9)$ & $10(13.0)$ & 0.001 \\
\hline
\end{tabular}

Data are presented as $\mathrm{n}(\%)$.

TIVA=total intravenous anesthesia, MACE=major adverse cardiac events, $n=n u m b e r$ 
The six MACE cases in the LA group were due to postoperative, non-ST elevated myocardial infarction (NSTEMI) in three cases, cardiac arrest; mainly from massive bleeding of surgical complications in two cases, and perioperative congestive heart failure, probably related to volume overload in one case. Likewise, in the propofolbased TIVA group, the MACE were NSTEMI with CHF in one case, acute postoperative ischemic stroke in one case, hypoxic arrest due to airway obstruction from over sedation at recovery room in one case, profound hypotension with ventricular tachycardia after bolus dose of propofol intraoperatively in one case, two cases with uncontrolled labile blood pressure (severe hypertension; then profound hypotension), acidosis from reperfusion syndrome, congestive heart failure and surgical complications (retroperitoneal hemorrhage).

We performed univariate and multivariate analyses to find the independent risk factors of perioperative MACE (Table 4 and Table 5, respectively). We found that $\mathrm{BMI}$ and $\mathrm{ASA}$ classification $\geq \mathrm{III}$ were associated with the incidence of perioperative MACE. However, no associations were found between patient characteristics and underlying diseases that included hypertension, diabetes mellitus, previous CAD, previous $\mathrm{CHF}$, previous stroke, and creatinine $>2 \mathrm{mg} / \mathrm{dL}$, or clinical presentation and technique of anesthesia with perioperative MACE.

Table 4 Univariate analysis of independent risk factors associated with perioperative and postoperative major adverse cardiac events and non-major adverse cardiac events outcomes

\begin{tabular}{|c|c|c|c|}
\hline MACE & Yes $(n=12)$ & No $(n=219)$ & $p$-value \\
\hline Age, years, median (IQR) & $71(62.8,85.2)$ & $72(61.0,79.0)$ & 0.346 \\
\hline Body weight, kg, median (IQR) & $49.5(44.8,53.2)$ & $57(49.0,65.0)$ & 0.056 \\
\hline Height, $\mathrm{cm}$, mean \pm S.D. & $162.6 \pm 8.4$ & $160.7 \pm 8.2$ & 0.433 \\
\hline BMI, kg/m², mean \pm S.D. & $19.3 \pm 2.6$ & $22.1 \pm 3.6$ & 0.011 \\
\hline ASA classification & & & 0.014 \\
\hline$I-I \mid$ & $2(16.7)$ & $116(53.0)$ & \\
\hline$\geq I I I$ & $10(83.3)$ & $103(47.0)$ & \\
\hline Hypertension & $10(83.3)$ & 167 (76.3) & 0.737 \\
\hline Diabetes mellitus & $5(41.7)$ & $115(52.5)$ & 0.663 \\
\hline Previous CAD & $4(33.3)$ & $41(18.7)$ & 0.256 \\
\hline Previous CHF & $2(16.7)$ & $13(5.9)$ & 0.178 \\
\hline Previous stroke & $2(16.7)$ & $18(8.2)$ & 0.278 \\
\hline Creatinine $>2 \mathrm{mg} / \mathrm{dL}$ & $5(41.7)$ & $51(23.3)$ & 0.169 \\
\hline Clinical presentation & & & 1.000 \\
\hline Claudication & $3(25.0)$ & $51(23.3)$ & \\
\hline Critical limb ischemia & $9(75.0)$ & $168(76.7)$ & \\
\hline Technique of anesthesia & & & 0.221 \\
\hline Local anesthesia & $6(50.0)$ & $148(67.6)$ & \\
\hline TIVA & $6(50.0)$ & $71(32.4)$ & \\
\hline
\end{tabular}

Data are presented as $\mathrm{n}(\%)$ unless indicated otherwise.

MACE=major adverse cardiac events, IQR, interquartile range, S.D.=standard deviation, $\mathrm{kg}=\mathrm{kilogram}, \mathrm{cm}=$ centimeter, $\mathrm{m}^{2}=\mathrm{square}$ meter, $\mathrm{BMl}=$ body mass index, $\mathrm{ASA}=\mathrm{American}$ Society of Anesthesiologists, $\mathrm{CAD}=$ coronary artery disease, $\mathrm{CHF}=$ congestive heart failure, $\mathrm{mg} /$ $\mathrm{dL}=$ milligram per deciliter, TIVA=total intravenous anesthesia, $n=$ number 
Table 5 Multivariate analysis of independent factor associated with major adverse cardiac events

\begin{tabular}{llll}
\hline Factor & Crude OR (95\% CI) & Adjusted OR (95\% CI) & p-value \\
\hline Body mass index & $0.78(0.65,0.95)$ & $0.77(0.64,0.94)$ & 0.005 \\
ASA classification III & $5.63(1.21,26.29)$ & $6.6(1.37,31.66)$ & 0.018 \\
$\begin{array}{l}\text { (Ref: classification I-II) } \\
\text { Technique of anesthesia }\end{array}$ & $2.08(0.65,6.69)$ & $1.81(0.48,6.85)$ & 0.387 \\
(Ref: local anesthesia) & & & \\
\hline
\end{tabular}

OR=odds ratio, $\mathrm{Cl}=$ confidence interval, $\mathrm{ASA}=$ American Society of Anesthesiologists

Table 6 Multivariate analysis of independent factors associated with minor perioperative complications

\begin{tabular}{llll}
\hline Factor & Crude OR $(95 \% \mathrm{Cl})$ & Adjusted OR $(95 \% \mathrm{Cl})$ & p-value \\
\hline Propofol-based TIVA & $21.98(10.82,44.67)$ & $65.24(22.77,186.9)$ & $<0.001$ \\
Body weight & $0.95(0.93,0.98)$ & $0.92(0.88,0.96)$ & $<0.001$ \\
Hypertension & $2.81(1.33,5.96)$ & $4.52(1.37,14.86)$ & 0.009 \\
Diabetes mellitus & $1.1(0.64,1.9)$ & $3.42(1.27,9.25)$ & 0.010 \\
Coronary artery disease & $2.63(1.35,5.12)$ & $2.76(1.02,7.48)$ & 0.043 \\
Previous CHF & $5.82(1.79,18.93)$ & $7.66(1.77,33.07)$ & 0.005 \\
\hline
\end{tabular}

OR=odds ratio, $\mathrm{Cl}=$ confidence interval, TIVA=total intravenous anesthesia, $\mathrm{CHF}=$ congestive heart failure

After that, a further analysis to identify the risk factors of perioperative minor complications was done and we found that using propofol-based TIVA, body weight (or $\mathrm{BMI}$ ), history of hypertension, history of diabetes mellitus, previous CAD, and previous CHF were associated with perioperative minor complications (Table 6).

\section{Discussion}

The risks of perioperative MACE and minor complications were demonstrated in patients undergoing PTA in lower extremities; using both propofol-based TIVA provided by anesthesiologist and LA anesthesia carried out by an interventionist. Significant higher events of minor complications, mainly due to propofol side effects, was shown in the propofol-based TIVA than that of the LA group.
Sedation and anesthesia are essential procedures for performing surgical intervention. However, the mechanisms of various sedatives or anesthetic drugs used are different, and result in a variation of side effects which require vigorous monitoring of the hemodynamic status for the principles of patient safety. ${ }^{25}$ One randomized-controlled trial study ${ }^{26}$ in 40 patients underwent PTA found that propofol-based TIVA had less respiratory depression than midazolam and no significant difference in blood pressure with no incidence of hypotension when achieved the same level of sedation at conscious sedation, however the dosage of propofol in the study was considerably low (46.7 $\pm 24.2 \mathrm{mg})$ compared to our current practice.

The perioperative MACE in our study was found in $3.9 \%$, which was in the range of previous studies; which was reported to be $1.0-6.6 .^{27,28}$ The difference of 
incidence detected might be because of different patient characteristics, regimens of anesthesia or definitions of perioperative MACE. The perioperative MACE could be resulted from the combined multifactorial causes of which a previous study suggested a cardiac risk index for predicting major noncardiac surgery ${ }^{29}$, and the guidelines on perioperative cardiovascular evaluation and management of patients undergoing noncardiac surgery. ${ }^{30}$

Our study found that BMI and ASA classification III were an independent risk factor of perioperative MACE in patients who underwent PTA in the lower extremity. A previous retrospective study, that had similar results with this study, showed no association between the patient's age and perioperative MACE in patients who underwent PTA in the lower extremity. ${ }^{27}$ In our study, low BMI was the independent factor that had a significant association with perioperative MACE. This could imply that obese patients possibly had closer monitoring during the perioperative care than non-obese patients in our practice; therefore, the term "obesity paradox" ${ }^{31}$ might be considered. A previous study in CAD also reported that patients who had a BMI between 30 and $40 \mathrm{~kg} / \mathrm{m}^{2}$ had a decrease in all-cause mortality. ${ }^{32}$ In contrast, the multivariate analysis in a previous study $^{28}$ found that diabetes mellitus and chronic renal failure were independent factors associated with perioperative MACE. This might be explained by the relatively lower sample size and incidence ofperioperative MACE in our study.

Propofol-based TIVA was the independent risk factors associated with perioperative minor complications in patients who underwent lower extremity PTA in our study. These perioperative minor complications can lead to life-threatening events if not promptly managed ${ }^{33}$ which require an experienced anesthesiologist, well-prepared resuscitation equipment, and standard monitoring including capnography. ${ }^{34}$ These actions would provide a prompt response to any event during the procedure, especially anesthesia in the remote area that usually have limited resources.

The results of our study suggested that MACE as well as minor perioperative complications were not uncommon, particularly in patients using propofol-based TIVA. These complications should be acknowledged and carefully prevented; even when propofol-based TIVA is performed by an experienced anesthesiologist.

There are several limitations because this is a retrospective cohort study. Firstly, the different interval of blood pressure recording time between two groups might affect the result. The propofol-based TIVA group received more frequent blood pressure monitoring and might be one of the reasons that we found a higher incidence of hypotension, however it could not fully explain the higher incidence of vasopressor used. Secondly, this study may have selection bias that unintentionally excluded patients who had severe cardiopulmonary compromise because this condition is a contraindication to perform propofolbased TIVA, which they underwent general anesthesia with endotracheal tube with balanced technique with volatile anesthetics instead. Thirdly, the induction and maintenance rate of propofol-based TIVA was not documented in the anesthetic record since the optimal dosage is adjusted by the attending anesthesiologist according to the condition of the patient. The other limitation is that we could not assess the depth of anesthesia or sedation in the propofol-based TIVA group because this is a retrospective cohort study and the patients who received propofol-based TIVA in our institute did not routinely monitor the bispectral index or record the clinical assessment of sedation depth. Lastly, we calculated the sample size based on the prevalence of the outcomes from previous studies which were quite different compared to our findings. Hence, the main reason of the non-significant difference of MACE between groups might be from the insufficient sample size to detect a 
difference between the groups. From our results, the power of two independent proportions was calculated and it was considerably low at $23.1 \%$.

\section{Conclusion}

The occurrence of perioperative, major adverse cardiac events was not significantly different between patients undergoing PTA in the lower extremity between those using propofol-based TIVA and those using local anesthesia. However, minor perioperative complications, such as hypotension, arrhythmia, airway intervention or the need of vasopressor were more likely to be found in propofol-based TIVA, therefore, close intraoperative monitoring is important and complications during the propofol-based TIVA procedure in patients who undergo PTA in the lower extremity should be prevented.

\section{Conflict of interest}

The authors declared no potential conflicts of interest with respect to the research, authorship, and/or publication of this article.

\section{References}

1. Fowkes FG, Rudan D, Rudan I, Aboyans V, Denenberg JO, McDermott MM, et al. Comparison of global estimates of prevalence and risk factors for peripheral artery disease in 2000 and 2010: a systematic review and analysis. Lancet 2013;382:1329-40.

2. Nowygrod R, Egorova N, Greco G, Anderson P, Gelijns A, Moskowitz A, et al. Trends, complications, and mortality in peripheral vascular surgery. J Vasc Surg 2006;43:205-16

3. Soder HK, Manninen HI, Jaakkola P, Matsi PJ, Räsänen HT, Kaukanen E, et al. Prospective trial of infrapopliteal artery balloon angioplasty for critical limb ischemia: angiographic and clinical results. J Vasclnterv Radiol 2000;11:1021-31.

4. Balmer H, Mahler F, Do DD, Triller J, Baumgartner I. Balloon angioplasty in chronic critical limb ischemia: factors affecting clinical and angiographic outcome. J EndovascTher 2002;9: 403-10.
5. Nasr MK, McCarthy RJ, Hardman J, Chalmers A, Horrocks M. The increasing role of percutaneous transluminal angioplasty in the primary management of critical limb ischaemia. Eur $\mathrm{J}$ Vasc Endovasc Surg 2002;23:398-403.

6. Faglia E, Dalla PL, Clerici G, Clerissi J, Graziani L, Fusaro M, et al. Peripheral angioplasty as the first-choice revascularization procedure in diabetic patients with critical limb ischemia: prospective study of 993 consecutive patients hospitalized and followed between 1999 and 2003. Eur J VascEndovasc Surg 2005;29:620-7.

7. Haslam PJ, Yap B, Mueller PR, Lee MJ. Anesthesia practice and clinicaltrends in interventional radiology: a European survey. Cardiovasc Interv Radiol 2000;23:256-61.

8. Mueller PR, Wittenberg KH, Kaufman JA, Lee MJ. Patterns of anesthesia and nursing care for interventional radiology procedures: anational survey of physician practices and preferences. Radiology 1997;202:339-43.

9. Graaf RA, Samuels N, Mulder M, Eralp I, van Es ACGM, Dippel DWJ, et al. Conscious sedation or local anesthesia during endovascular treatment for acute ischemic stroke. Neurology 2018;91:e19-25.

10. Li FH, Deshaies EM, Singla A, Villwock MR, Melnyk V, Gorji $\mathrm{R}$, et al. Impact of anesthesia on mortality during endovascular clot removal for acute ischemic stroke. J Neurosurg Anesthesiol 2014;26:286-90.

11. Ding DY, Mahure SA, Mollon B, Shamah SD, Zuckerman JD, Kwon YW. Comparison of general versus isolated regional anesthesia in total shoulder arthroplasty: a retrospective propensity-matched cohort analysis. J Orthop 2017;14:417-24.

12. Leichtle SW, Mouawad NJ, Welch K, Lampman R, Whitehouse WM Jr, Heidenreich M. Outcomes of carotid endarterectomy under general and regional anesthesia from the American college of surgeons' national surgical quality improvement program. J Vasc Surg 2012;56:81-8.

13. Vaniyapong T, Chongruksut W, Rerkasem K. Local versus general anaesthesia for carotid endarterectomy. Cochrane Database Syst Rev 2013;12:CD000126.

14. Dakour AH, Paracha N, Nejim B, Locham S, Malas MB. Anesthetic type and hospital outcomes after carotid endarterectomy from the vascular quality initiative database. J Vasc Surg 2018;67:1419-28.

15. Broos PP, Stokmans RA, Cuypers PW, van Sambeek MR, 
Teijink JA. Effects of anesthesia type on perioperative outcome after endovascular aneurysm repair. J Endovasc Ther 2015;22:770-7.

16. Hajibandeh S, Adasonla K, Antoniou SA, Antoniou SA, Barrie J, Madan M. Loco-regional versus general anaesthesia for elective endovascular aneurysm repair - results of a cohort study and a meta-analysis. Vasa 2018;47:209-17.

17. Noh M, Choi BM, Kwon H, Han Y, Ko GY, Kwon TW, et al. General anesthesia versus local anesthesia for endovascular aortic aneurysm repair. Medicine (Baltimore) 2018;97. doi: 10.1097/MD.0000000000011789

18. Perlas A, Chan VW, Beattie S. Anesthesia technique and mortality after total hip or knee arthroplasty: a retrospective, propensity score-matched cohort study. Anesthesiology 2016; 125:724-31.

19. Johnson RL, Kopp SL, Burkle CM. Neuraxial vs general anaesthesia for total hip and total knee arthroplasty: a systematic review of comparative-effectiveness research. $\mathrm{Br}$ J Anaesth 2016;116:163-76.

20. Johnston KW, Rae M, Hogg-Johnston SA, Colapinto RF, Walker PM, Baird RJ, et al. 5-year results of a prospective study of percutaneous transluminal angioplasty. Ann Surg 1987;206:403-13.

21. Morris-Stiff G, Moawad M, Appleton N, Davies G, Hicks E, Davies C, et al. Long-term clinical outcome following lower limbarterial angioplasty. Ann R Coll Surg Engl 2011;93:250-4.

22. Peregrin JH, Koznar B, Kovác J, Lastovicková J, Novotný J, Vedlich D, et al. PTA of infrapopliteal arteries: long-term clinical follow-up and analysis of factors influencing clinical outcome. Cardiovasc Intervent Radiol 2010;33:720-5.

23. Schreuder SM, Hendrix YMGA, Reekers JA, Bipat S. Predictive parameters for clinical outcome in patients with critical limb ischemia who underwent percutaneous transluminal angioplasty (PTA): asystematic review. Cardiovasc Intervent Radiol 2018;41:1-20.

24. Jehad A, Jayanth A, Noor A, Sumaya L, Mouaz A, Larry JP, et al. A systematic review and meta-analysis of revascularization outcomes of infrainguinal chronic limb-threatening ischemia. J Vasc Surg 2018;68:624-33.

25. David MG. Anaesthesiology as a model for patient safety in health care. BMJ 2000;320:785-8.

26. Wagner HJ, Nowacki J, Klose KJ. Propofol versus midazolam for sedation during percutaneous transluminal angioplasty. JVIR 1996;7:673-680.

27. Kimmelstiel C, Pinto D, Aronow HD, Weintraub AR, Dangas G, Fan W, et al. Bivalirudin is associated with improved inhospital outcomes compared with heparin in percutaneous vascular interventions: observational, propensity-matched analysis from the premier hospital database. Circ Cardiovasc Interv 2016;9:e002823.

28. Plaisance BR, Munir K, Share DA, Mansour MA, Fox JM, Bove $P G$, et al. Safety of contemporary percutaneous peripheral arterial interventions in the elderly insights from the BMC2 PVI (Blue Cross Blue Shield of Michigan Cardiovascular Consortium Peripheral Vascular Intervention) registry. JACC Cardiovasc Interv 2011;6:694-701.

29. Lee TH, Marcantonio ER, Mangione CM, Thomas EJ, Polanczyk CA, Cook EF, et al. Derivation and prospective validation of a simple index for prediction of cardiac risk of major noncardiac surgery. Circulation 1999;100:1043-9.

30. Fleisher LA, Fleischmann KE, Auerbach AD, Barnason SA, Beckman JA, Bozkurt B, et al. 2014 ACC/AHA guideline on perioperative cardiovascular evaluation and management of patients undergoing noncardiac surgery: a report of the American College of Cardiology/American Heart Association Task Force on practice guidelines. J Am Coll Cardiol 2014;64: 77-137.

31. Carnethon MR, De Chavez PJ, Biggs ML, Lewis CE, Pankow JS, Bertoni AG, et al. Association of weight status with mortality in adults with incident diabetes. JAMA 2012;308:581-90.

32. Angeras $\mathrm{O}$, Albertsson $\mathrm{P}$, Karason $\mathrm{K}$, Råmunddal $\mathrm{T}$, Matejka G, James $S$, et al. Evidence for obesity paradox in patients with acute coronary syndromes: a report from the Swedish Coronary Angiography and Angioplasty Registry. Eur Heart J 2013;34:345-53.

33. Monk TG, Bronsert MR, Henderson WG, Mangione MP, Sum-Ping ST, Bentt DR, et al. Association between intraoperative hypotension and hypertension and 30-day postoperative mortality in noncardiac surgery. Anesthesiology 2015;123:307-19.

34. Beitz A, Riphaus A, Meining A, Kronshage T, Geist C, Wagenpfeil $S$, et al. Capnographic monitoring reduces the incidence of arterial oxygen desaturation and hypoxemia during propofol sedation for colonoscopy: a randomized, controlled study. Am J Gastroenterol 2012;107:1205-12. 